\title{
The Need for Social Accountability in Medical School Education: a Tale of Five Students' Integration into Vancouver's Downtown Eastside
}

\author{
Taren Roughead, BSc ${ }^{1}$, Hira Gill, BSc ${ }^{1}$, Krista Dewar, $\mathrm{BSc}^{1}$, Naomi Kasteel, BSc ${ }^{1}$, \\ Kimberly Hamilton, BSc ${ }^{1}$
}

${ }^{1}$ Faculty of Medicine, University of British Columbia

A B STRACT

Medical educators are recognizing that social accountability is a tenet of Canadian medical education, yet it is a difficult concept to teach didactically. Accumulating evidence supports the integration of social accountability into the medical curriculum through community involvement. Fortunately, the University of British Columbia Faculty of Medicine enables students to pursue community learning as part of its curriculum; and we, five medical students, benefited from that opportunity. This commentary will promote the importance of teaching social accountability in medical schools through community-based learning based on available literature and our personal experience with Vancouver's Downtown Eastside (DTES).

\section{RÉ S U MÉ}

Les professeurs de médecine reconnaissent que la responsabilité sociale est un pilier de l'éducation médicale canadienne; néanmoins, c'est un concept difficile à enseigner didactiquement. De plus en plus de preuves appuient l'intégration de la responsabilité sociale au curriculum médical à travers l'engagement communautaire. Heureusement, la Faculté de Médecine de l'Université de la Colombie-Britannique permet aux étudiants de participer à l'apprentissage par engagement communautaire en tant que composante du curriculum; nous, cinq étudiants en médecine, avons pu profiter de cette opportunité. Ce commentaire va promouvoir l'importance d'enseigner la responsabilité sociale dans les écoles de médecine par l'intermédiaire de l'apprentissage par engagement communautaire, basé sur la littérature disponible et notre expérience personnelle avec le quartier de Downtown Eastside de Vancouver (DTES).

\section{INTRODUCTION}

The World Health Organization (WHO) defines the social accountability of medical schools as "the obligation to direct their education, research and service activities towards addressing the priority health concerns of the community, region, and/or nation they have a mandate to serve" [1]. Moreover, the Association of Faculties of Medicine of Canada has established social accountability as a fundamental value of Canadian medical schools and, in turn, physicians [2]. In 2010, 130 organizations and individuals who are leaders in medical education, accreditation, and social accountability conferred and developed the Global Consensus for Social Accountability of Medical Schools which provides ten strategies for medical schools to become socially accountable [3]. The CanMEDS framework was designed by the Royal College of Physicians and Surgeons of Canada to establish standards of physicians to adequately meet the health care needs of their patients. The role of Health Advocate integrates social accountability: "Physicians are accountable to society and recognize their duty to contribute to efforts to improve the health and well-being of their patients, their communities, and the broader populations they serve" [4]. Medical schools are embracing the importance of social accountability, but it is necessary to find an effective method of conveying this value to students. Many students start medical school

Keywords: Education; Medical School; Social Accountability; Community with "altruistic motives, including working with underserved populations," but unfortunately do not prioritize these values after finishing medical school and before starting practice [5]. Educational modules incorporating community experiences into the curriculum may encourage students to retain these values and help raise awareness of healthcare needs in underserviced communities [6]. Social accountability is a central component of health care professions, and can be integrated into medical education through community-based learning.

Multiple studies have demonstrated the positive outcomes of medical student involvement in the community. A systematic review established that community involvement fostered a better understanding of health disparities, barriers to health care, social determinants of health, cultural competency, and professionalism [7]. Understanding individual challenges and barriers enables physicians to provide better personalized medical care. Through the University of British Columbia (UBC) medical school course "Doctor, Patient, and Society" (DPAS), second year medical students are offered a community service option as an alternative to classroom based learning. A pilot study by Dharamsi et al found that students engaged in this DPAS community service learning course had developed a sense of social responsibility and a strong understanding of the challenging experiences of marginalized populations by questioning their "taken-for-granted assump- 
tions" [8]. In 2012, a group of UBC medical students participated in prison health care through DPAS and worked in direct contact with this marginalized population. Thematic analysis from an in-depth interview of their experiences indicated that students benefitted by: (1) developing insight into the difficulties facing marginalized sub-populations through contact with inmates; (2) building relationships with inmates through positive interactions; (3) enhancing their teamwork skills through collaboration; and (4) gaining important learning opportunities through community service involvement [9]. A thorough appreciation of the challenges faced by marginalized populations will help healthcare professionals provide services that better address the needs for this group. Moreover, relationships with disparaged persons may prevent illness and morbidity. Continuing community engagement of medical students with marginalized populations reinforces students' sense of altruism that they had when they entered medical school. This is important because medical students' attitudes toward marginalized populations become increasingly negative as they progress through their medical education [10].

We, five medical students from UBC, strongly benefited from our DPAS experience with the Vancouver Street Soccer League (VSSL), a non-profit organization that encourages members of Vancouver's Downtown Eastside (DTES) to play soccer in a safe and friendly environment. Residents of Vancouver's DTES comprise one of the most marginalized populations in Canada: 22\% are unemployed and $45 \%$ are dependent on government transfer payments [11]. The VSSL mandates to provide social support for the homeless, exercise for the addicted, and guidance for youth. In addition, the VSSL aims to improve teamwork, communication skills, and confidence amongst its members. A standout feature of the VSSL is that it incorporates players on the governing board; these players, in turn, provide firsthand experience and vote on new propositions and endeavours. Through this model, longtime players support new players, and benevolence pervades the organization and the VSSL community which establishes an early preventative medicine strategy.

Our group invited UBC medical students to play monthly soccer games with VSSL players from the DTES and coached a weekly practice specifically for female players from the VSSL. By facilitating interaction between medical students and marginalized individuals in an informal environment outside of the typical healthcare setting, we intended for these groups to build positive relationships with each other. On one hand, members of the DTES would appreciate that future medical professionals can be sympathetic and trustworthy people, thereby fostering long-term relationships with future healthcare providers. On the other hand, participating medical students would gain perspective into the lives of residents of the DTES with the goal of being able to better serve this population in the future. Moreover, research shows that students who are exposed to and involved in programs tar- geting underserved areas, such as the DTES, are more likely to practice in these communities in the future $[12,13]$. An increased density of primary care physicians in underserved communities can be an excellent resource for preventative medicine. Building strong relationships with vulnerable individuals would also help health care practitioners to personalize medicine. Finally, women of the DTES face unique and complicated challenges when accessing healthcare, and we anticipated that building meaningful relationships through these soccer practices may counter some of these difficulties. To illustrate, women who are living on the street, such as in the DTES, have disproportionately more bloodborne diseases, sexually transmitted infections, unplanned pregnancies, mental health problems, problematic substance abuse, malnutrition, and chronic illness [14]. These women also face barriers to health care including lack of respect and judgement from providers [15]. So to create a more comfortable and secure playing environment, we proposed holding female-only practice sessions which helped foster more positive relationships between the female members of the DTES community and UBC medical students.

Despite the increasingly recognized importance of teaching and promoting social accountability in the medical school curriculum, it is unclear what may be considered sufficient. Longitudinal studies have demonstrated clear benefits. For example, one study, which determined an increased likelihood of medical students becoming physicians for underserviced areas, integrated a longitudinal curriculum involving all four year of medical school [13]. Nevertheless, research has shown a benefit from the DPAS course, and we feel that the DPAS course, despite lasting only one year, has positively impacted our experience [8,9]. Furthermore, our group continues to be informally involved with the VSSL and attends monthly games arranged by a new cohort of medical students for their DPAS course.

From our participation in the VSSL, we have developed a greater awareness of ethnic, social, cultural, and gender diversity. The Global Consensus for Social Accountability of Medical Schools suggests that one of the challenges of medical education is "improving quality, equity, relevance and effectiveness in health care delivery [and] reducing mismatch with societal priorities [while] redefining roles of health professionals" [3]. Medical schools are embracing these challenges, and we have benefited from UBC's progressive implementation of social education opportunities in the curriculum. Studies have also shown that the UBC medical school DPAS course enables students to "challenge their takenfor-granted assumption about vulnerable communities" and to harvest a "deeper appreciation among future health practitioners of the vulnerabilities that marginalized segments of the population experience" [8]. In conclusion, social accountability is an integral component of medical school education, as shown by both research and firsthand experience, and we believe that 
it can be most effectively learned through community-based learning modules.

\section{REFERENCES}

1. Boelen C, Heck J. Defining and measuring the social accountability of medical schools [Internet]. Geneva: World Health Organization; [cited 2016 Jan 6]. Available from: http://apps.who.int/iris/bitstream/10665/59441/1/WHO_HRH_95.7.pdf.

2. Busing $\mathrm{N}$, Rosenfield J, Rourke J. The Future of Medical Education in Canada (FMEC): A Collective Vision for MD Education [Internet]. Ottawa: The Association of Faculties of Medicine of Canada (AFMC); 2010 [cited 2016 Jan 6]. Available from: https://www.afmc.ca/future-of-medicaleducation-in-canada/medical-doctor-project/pdf/collective_vision.pdf.

3. Awases M, Bailey R, Boelen C, et al. Global Consensus for Social Accountability of Medical Schools [Internet]. Global Consensus for Social Accountability of Medical Schools; 2010 Dec [cited 2016 Jan 6]. Available from: http://healthsocialaccountability.sites.olt.ubc.ca/files/2011/06/1106-07-GCSA-English-pdf-style.pdf.

4. Health Advocate [Internet]. Ottawa (ON): The Royal College of Physicians and Surgeons of Canada. 2015. Available from: http://www.royalcollege. $\mathrm{ca} /$ portal/page/portal/rc/canmeds/framework/health_advocate.

5. Coulehan J, Williams P. Vanquishing Virtue: The Impact of Medical Education. Acad Med. 2001;76(6):598-605.

6. Meili R, Fuller D, Lydiate J. Teaching social accountability by making the links: Qualitative evaluation of student experiences in a service-learning project. Med Teach. 2011;33(8):659-66.

7. Hunt J, Bonham C, Jones L. Understanding the Goals of Service Learning and Community-Based Medical Education: A Systematic Review. Acad Med. 2011;86(2):246-51.

8. Dharamsi S, Espinoza N, Cramer C, Amin M, Bainbridge L, Poole G. Nurturing social responsibility through community service-learning: Lessons learned from a pilot project. Med Teach. 2010;32(11):905-11.

9. Filek H, Harris J, Koehn J, Oliffe J, Buxton J, Martin R. Students' experience of prison health education during medical school. Med Teach. 2013;35(11):938-43.

10. Crandall S, Reboussin B, Michielutte R, Anthony J, Naughton M. Medical Students' Attitudes Toward Underserved Patients: A Longitudinal Comparison of Problem-Based and Traditional Medical Curricula. Adv Health Sci Educ Theory Pract. 2007;12(1):71-86.

11. Linden IA, Mar MY, Werker GR, Jang K, Krausz M. Research on a Vulnerable Neighborhood - The Vancouver Downtown Eastside from 2001 to 2011. J Urban Health. 2013;90(3):559-573.

12. Haq C, Stearns M, Brill J, Crouse B, Foertsch J, Knox K, Stearns J, Skochelak $\mathrm{S}$, Golden R. Training in Urban Medicine and Public Health: TRIUMPH. Acad Med. 2013;88(3):352-63.

13. Roy V, Hurley K, Plumb E, Castellan C, McManus P. Urban underserved program: an analysis of factors affecting practice outcomes. Fam Med. 2015;47(5):373-7.

14. Bungay V. Health Care Among Street-Involved Women: The Perpetuation of Health Inequity. Qual Health Res. 2013;23(8):1016-26.

15. Ensign J, Panke A. Barriers and bridges to care: voices of homeless female adolescent youth in Seattle, Washington, USA. J Adv Nurs. 2002 Jan;37(2):166-72. 